\title{
Changes over time in the relationship between weight, body fat, motivation, impulsivity and eating behaviour
}

\author{
Paula Foscarini-Craggs ${ }^{*}$ (D) , Rob Lowe ${ }^{2}$ and Michelle Lee ${ }^{2}$
}

\begin{abstract}
Background: University students are at a greater risk of gaining weight compared to others. We explored associations between changes in weight and a set of dispositional constructs related to eating behaviour: motivation, impulsivity, social comparison, and eating styles. We predicted that increases in controlled motivation, impulsivity, uncontrolled eating, emotional eating, and physical appearance comparison would be related to increased weight and body fat.

Methods: First year students at a British university completed baseline $(n=196)$ and three-month $(n=163)$ measures of impulsivity, physical appearance comparison, motivation for following a healthy diet, eating styles, weight and body fat. Baseline-follow-up changes in these constructs were computed and subjected to cluster analysis.

Results: Four participant groups were identified according to similarities in the way these constructs evolved over time. The Losing and Gaining groups tended to show opposing changes in key variables (physical appearance comparison, uncontrolled eating, motivation, weight, and percentage of body fat). Interestingly, two groups showed no change in weight and body fat but evidenced unique changes in key variables, indicating that individuals can have different psychological profiles but still maintain their weight.

Conclusions: The study highlighted how stable weight maintenance arises from sets of interdependent constructs rather than variables in isolation, as well as emphasizing a need to take a person-centred approach to examining those at risk of weight gain and in developing interventions.
\end{abstract}

Keywords: 'Freshman 15', Self-determination theory, Impulsivity, Weight change, Eating behaviour

\section{Background}

Moving from home to university represents a life change, often necessitating redevelopment of healthrelated habits. Environment changes can disrupt established habits because pre-existing behavioural cues are no longer present [1-3]. Attitudes, motivation, and poor self-control influence the development of unhealthy habits when in new environments [3-5]. This study

\footnotetext{
*Correspondence: Foscarini-CraggsP@Cardiff.ac.uk

${ }^{1}$ Centre for Trials Research, Cardiff University, Cardiff, UK

Full list of author information is available at the end of the article
}

examined changes in motivation, impulsivity, social comparison, and eating styles to identify patterns of change associated with weight gain in first-year university students.

Weight change in first year university students ranges from $0.83 \mathrm{~kg}$ to $4.5 \mathrm{~kg}[6,7]$, and is independent of changed height [8-10]. University students gain weight quicker than their peers not in university [11]. Implicated in this weight gain are high-fat foods present in dining halls, frequent snacking, drinking alcohol [12-16] and a decrease in physical activity $[7,8,17,18]$.

C C The Author(s). 2021 Open Access This article is licensed under a Creative Commons Attribution 4.0 International License, which permits use, sharing, adaptation, distribution and reproduction in any medium or format, as long as you give appropriate credit to the original author(s) and the source, provide a link to the Creative Commons licence, and indicate if changes were made. The images or other third party material in this article are included in the article's Creative Commons licence, unless indicated otherwise in a credit line to the material. If material is not included in the article's Creative Commons licence and your intended use is not permitted by statutory regulation or exceeds the permitted use, you will need to obtain permission directly from the copyright holder. To view a copy of this licence, visit http://creativecommons.org/licenses/by/4.0/ The Creative Commons Public Domain Dedication waiver (http://creativecommons.org/publicdomain/zero/1.0/) applies to the data made available in this article, unless otherwise stated in a credit line to the data. 
However, not all students gain weight, suggesting specific risk factors are present.

Research has examined individual variables facilitating weight gain $[6,9,17,19]$, by exploring trends across the whole sample in specific eating traits (eating restraint, uncontrolled eating), and interpersonal relationships and dispositional factors (impulsivity and motivation) on weight gain. Studies looking at healthy habits in adults show that individuals with a given healthy habit tend to have other healthy habits $[20,21]$. This suggests 'sets' or clusters of traits which support or maintain these healthy habits. The current study built on this research by examining a wider set of interrelated dispositional variables: motivation, impulsivity, eating styles, and social comparison. This study aimed to explore the extent to which these factors evolved over a 3-month period and combine together in their association with changing weight among new university attendees.

Regarding motivation, Self-Determination Theory [22] classifies the quality of motivation according to different orientations. Firstly, controlling which includes external regulation (motivated by reward or avoiding punishment) and introjected regulation (motivated by ego enhancement or avoiding guilt); secondly, autonomous which includes identified regulation (motivated by a goal) and intrinsic motivation (enjoyment of the behaviour) [22-24]. Autonomous motivation facilitates the development of healthy habits, with links to weight loss in students because it is goal oriented and driven by enjoyment of the behaviour [25-28].

Impulsivity can influence a person's food choices through impairments in their executive function, such as an inability to defer gratification and increased disinhibition [27-32]. In students, impulsivity is related to higher consumption of saturated fats and snacking through uncontrolled and emotional eating [6, 33-36]. Negative effects of impulsivity can be mitigated by boosting executive function through increasing autonomous motivation [37-39].

Restrained eating is restricting dietary intake to lose or maintain weight $[6,19,40]$. However, there is no clear relationship between restrained eating and weight change in university students $[10,19,41,42]$. For example, elevated dietary restraint is associated with weight loss [41] as well as weight gain [19]. The current study aims to determine whether other factors, operating in conjunction with restrained eating, place individuals at greater or lower risk of gaining weight.

Social comparison orientation is a tendency to compare and modify behaviour based on perceived norms [43-48] and is related to controlled motivation due to the pressure of normative influence [49-52]. Social comparison is associated with changed eating behaviour based on perceived physical appearance and body size norms of the reference group [53-56]. Thus, weight gain in students may be associated with social comparison and social activities centred around food.

Changes in psychological variables associated with lifestyle behaviours would be expected to lead to changes in those behaviours. For example, elevated impulsivity is associated with increased alcohol consumption in young adults $[57,58]$. Changes in social groups and environment may also impact motivation [22, 24, 49]. Cognitive restraint and social comparison orientation may be influenced by students' new social milieu. Students change their eating behaviour, and by extension dieting behaviour, based on friendship groups and this can further influence changes in physical appearance comparison [53, 59-61].

To summarise, entering university represents a critical life period, where young adults are at risk of developing unhealthy habits $[60,62,63]$. Our study builds on previous work by taking advantage of this critical period and longitudinally tracking changes over 3 months in both psychological traits and body fat/weight to identify clusters (sets) of psychological factors predisposing individuals to weight change. We hypothesized that new university students who increase body fat and/or weight will evidence decreased autonomous motivation (identified regulation, and intrinsic motivation) and decreased physical activity, but increased controlled motivation (external regulation and introjected regulation), impulsivity, physical appearance comparison, emotional eating, and uncontrolled eating. Those who decreased body fat and/or weight would show the opposite pattern.

\section{Method}

\section{Participants}

The baseline sample comprised 196 first-year students attending a UK university. There were three recruitment waves: Cohort A $(n=76)$, Cohort B $(n=82)$ and Cohort $\mathrm{C}(n=38)$. For each, follow-up occurred 3 months later, resulting in a follow-up sample of $n=163$ (83.2\% retention). Participants were primarily recruited through the psychology department but university-wide emails were also used. Participants were eligible if they were enrolled in their first year of their first undergraduate degree. Every effort was made to ensure the study recruited participants with a range of body sizes. Psychology participants $(89.28 \%$ of the sample) received study credits for each study session attended, whilst non-psychology participants received an entry to a draw for a cash prize for each attended session. Most participants who did not attend the second session did not respond to follow up reminders and only one participant declined to continue in the study. To address limitations in sample size, three cohorts were recruited. Ethical approval was given by the psychology departmental research ethics committee. 


\section{Measures $^{1}$}

Motivation for Eating was assessed with a questionnaire measure of extrinsic and intrinsic motivation towards eating a healthy diet. It was a modification of the SelfRegulation for Exercise scale [64], done by replacing references to exercise with references to healthy diet. Subscales measure the four types of motivation from selfdetermination theory: external regulation (four items), introjected regulation (three items), identified regulation (four items) and intrinsic motivation (four items) [49]. Response options ranged from 1 (not true for me) to 5 (true for me) and scored by averaging responses for each subscale. Higher scores indicate elevated motivational style. Alpha coefficient can be found in Table 1 .

Impulsivity was assessed with the Barratt Impulsiveness Scale-11 [65], comprising 30 items with a fourpoint Likert scale ranging from 1 (rarely/never) to 4 (almost always/always). Items implying lower impulsivity are reverse-scored and then all items summed. Higher scores indicate greater impulsivity. Alpha coefficient can be found in Table 1.

Eating Style: cognitive and behavioural components of eating were assessed using the brief version of the Three-Factor Eating Questionnaire [40] which has 18 items. Responses are recorded using a Likert scale, with labels varying according to sub-scale. There are three subscales: emotional eating (a tendency to eat to cope with negative emotions, three items), uncontrolled eating (an inability to effectively regulate food intake, nine items), and cognitive restraint (limiting food intake to control weight, six items). Subscales scores are derived by reverse coding items indicating less of the particular eating style and then summing across all items. Higher scores indicate a greater tendency to exhibit that particular eating style. Alpha coefficient can be found in Table 1.

Physical Appearance Comparison was assessed using The Physical Appearance Comparisons Scale (PACS) [66]. This measures the respondent's tendency to compare their physical appearance to others within their social circle and across different social situations. The questionnaire contains five items and uses a five pointe Likert scale ranging from 1 (never) to 5 (always). Items indicating a tendency to not compare are reversed coded and then all items are summed. Higher scores indicate a greater tendency to compare physical appearance with others. Alpha coefficient can be found in Table 1.

\footnotetext{
${ }^{1}$ Alcohol Consumption Habit: Participants were also asked to complete a measure of habitual consumption of alcoholic beverages over the preceding 6 months. This measure was not included in the current analyses; it was not completed by $22 \%$ of participants at baseline and $16 \%$ of participants at time-2. It appeared that participants had skipped several questions and there was no reliable way of replacing the missing data.
}

Table 1 Alpha Coefficients for Study Variables at Each Time Point

\begin{tabular}{lcc}
\hline Variable & T1 & T2 \\
\hline Controlled Motivation & & \\
External & 0.84 & 0.88 \\
Introjected & 0.89 & 0.93 \\
Autonomous Motivation & & \\
$\quad$ Identified & 0.73 & 0.72 \\
$\quad$ Intrinsic & 0.88 & 0.91 \\
Impulsivity & 0.84 & 0.87 \\
Eating Styles & & \\
Emotional Eating & 0.83 & 0.85 \\
Uncontrolled Eating & 0.71 & 0.76 \\
Cognitive Restraint & 0.61 & 0.79 \\
PACS & 0.63 & 0.74 \\
\hline
\end{tabular}

Time spent doing Physical Activity was assessed using a modified version of the 7 Day Physical Activity (PA) Recall [67], which measures level of physical activity over the preceding week. The original version comprises a one-to-one interview wherein participants recall how many days of the week they were physically active, for how long, and how strenuously. A modified version was used to enable self-reporting and was based on the method used by Lowe, Eves, and Carroll [68]. This comprised a list of common physical activities; participants indicated how many hours/minutes they pursued each activity for each day of the preceding week. In the current study, the measure assessed commitment to physical activity. Given the study's focus on motivation, there was a potential confound between time spent on an activity and energy expenditure, either of which can represent commitment, but which may be obscured by combining them in the normal way. We used time spent in activity to index commitment based on the assumption that someone committed to an activity will spend as much time as possible in its pursuance. To derive a single score, time (in minutes) was summed across all activity bouts.

Anthropometric measurements and demographic data: height, weight, and percentage of body fat were measured at each time point. Height (meters) was measured on a stadiometre (SECA laboratory Scales). A set of Tanita BF-350 scales [69] measured weight (kilograms) and percentage body fat, the latter indexed via bioelectrical impedance [69]. Age and gender were recorded during the baseline session.

\section{Procedure}

Participants were initially recruited over a month at the start of the academic year. Participants were contacted to attend the follow up session in the middle of January, 
following the Christmas break and exam period, via email and text message. Participants who did not respond were emailed or texted weekly across the following month to encourage them to attend a follow up session. At baseline and time-2, participants completed questionnaires on SurveyMonkey prior to being weighed. To obtain an accurate weight and for the use of the bioimpedance, participants were asked to remove their shoes, socks, jacket or jumper, and to take anything heavy (such as mobile phone or keys) out of their pockets prior to stepping on the scale.

\section{Statistical analysis}

The focus of the study was to identify unique clusters of people based on their degree of weight/body fat change and change in related key psychological variables during the first 3 months at university.

Following recommendations of Tabachnick and Fidell (2007), missing data that was limited to a single skipped item was replaced using the Expectation Maximization method and then scale values were computed for that questionnaire. At baseline and time-2, 8.23 and 11.28\% respectively of participants had one item replaced. Analyses were run with and without missing data and central findings were overall the same. Therefore, the set with the replaced data was kept so as to maximise sample size. At time-1, impulsivity (3 participants), physical activity (4 participants), and weight (3 participants) had data points omitted due to either missing data, or the data point was classified as an outlier $( \pm 3 S D)$. At time- 2 , impulsivity ( 2 participants), physical appearance comparison (1 participant), physical activity (1 participant), weight (7 participants), and percentage of body fat (5 participants) had data points omitted due to missing data or being outliers. Because we were looking at changes in clusters of variables, only participants with complete datasets were entered into the cluster analysis. This resulted in a total sample of 142 participants included in the final analysis.

The aim of this study was to explore how sets of traits change together over time and whether these changes are associated with changes in weight and body fat. The change in each study variable was computed as the unstandardized residual between its baseline and time- 2 score. The residual scores were then used in a cluster analysis to identify groups of participants who had a similar profile of change over time. Following Clatworthy et al. [70], a three step cluster analysis was used. First, a Ward analysis (squared Euclidian distances with no specified number of clusters) identified 4 clusters via the dendrogram and cluster coefficients. A second Ward analysis, specifying four clusters, determined cluster centroids for seeding the final K-means analysis used to identify final group membership for the (four) clusters.
The mean of each study variable in a given cluster was compared to the mean across the remaining three clusters. Differences were indexed by their effect sizes (Cohen's $d$ ). Salient variables had a medium to large effect size (Cohen's $d=+/-.05$; equivalent to a significance level of $p \leq .01$ ). In this way, it was possible to identify which variables were especially (un) characteristic as the cluster evolved over time. Effect sizes were used to address potential biases due to the sample size.

\section{Results}

Means and standard deviations for critical study variables at baseline and follow up, along with age and gender, are shown in Table 2.

\section{The gaining cluster}

Participants $(n=48)$ in this cluster evidenced a mean increase of $1.37 \mathrm{~kg}$ and $1.28 \%$ body fat. Across the cluster, there were increases in physical appearance comparison, external regulation, introjected regulation, identified regulation, as well as uncontrolled eating (See Fig. 1 for effect size values and Table 3 for means and change values).

\section{The losing cluster}

Participants $(n=25)$ in this cluster evidenced a decrease of $3.45 \mathrm{~kg}$, and $1.61 \%$ of body fat. This cluster also showed decreases in physical appearance comparison, uncontrolled eating, and the amount of time spent doing physical activity. There were increases in intrinsic motivation and in cognitive restraint (see Fig. 2 for effect size values and Table 3 for means and change values).

\section{The no change-high autonomous cluster}

Participants $(n=34)$ in this cluster showed a modest increase of $0.46 \mathrm{~kg}$ and $0.93 \%$ of weight and body fat but it was not statistically meaningful. Across the cluster, there were decreases of in physical appearance comparison, external regulation, introjected regulation, emotional eating, and cognitive restraint. There were increases in identified regulation, and intrinsic motivation (see Fig. 3 for effect size values, and Table 4 for means and change values).

\section{The no change-low autonomous cluster}

For participants $(n=35)$, the increase of $0.46 \mathrm{~kg}$ and the decrease of $0.34 \%$ of body was not statistically meaningful. Across the cluster, respondents evidenced decreased introjected regulation, identified regulation, intrinsic motivation, and cognitive restraint (see Fig. 4 for effect size values, and Table 4 for means and change values). 
Table 2 Means (SD) at Time 1 and Time 2 for total sample

\begin{tabular}{|c|c|c|c|}
\hline & $\mathrm{T} 1$ & $\mathrm{~T} 2$ & Change \\
\hline \multicolumn{4}{|l|}{ Controlled Motivation } \\
\hline External & $1.86( \pm 0.84)$ & $2.10( \pm 0.94)$ & $0.23( \pm 0.87)$ \\
\hline Introjected & $3.00( \pm 1.29)$ & $3.03( \pm 1.28)$ & $-0.01( \pm 1.08)$ \\
\hline \multicolumn{4}{|l|}{ Autonomous Motivation } \\
\hline Identified & $3.80( \pm 0.91)$ & $3.77( \pm 0.83)$ & $-0.04( \pm 0.71)$ \\
\hline \multirow[t]{2}{*}{ Intrinsic } & $3.31( \pm 1.01)$ & $3.42( \pm 1.09)$ & $0.08( \pm 0.82)$ \\
\hline & & & 14.26 \\
\hline Impulsivity & $63.61( \pm 10.16)$ & $78.14( \pm 14.90)$ & $14.26( \pm 10.61)$ \\
\hline \multicolumn{4}{|l|}{ Eating Styles } \\
\hline Emotional Eating & $7.00( \pm 2.77)$ & $6.86( \pm 2.64)$ & $-0.13( \pm 2.32)$ \\
\hline Uncontrolled Eating & $20.99( \pm 5.79)$ & $21.31( \pm 5.73)$ & $0.40( \pm 4.13)$ \\
\hline Cognitive Restraint & $14.61( \pm 4.11)$ & $15.09( \pm 4.75)$ & $0.35( \pm 3.83)$ \\
\hline PACS & $15.55( \pm 3.93)$ & $15.17( \pm 4.11)$ & $-0.33( \pm 2.78)$ \\
\hline PA (min/week) & $490.39( \pm 344.25)$ & $458.32( \pm 367.10)$ & $-26.07( \pm 311.28)$ \\
\hline Weight (Kg) & $64.36( \pm 11.68)$ & $62.96( \pm 11.04)$ & $0.41(2.44)$ \\
\hline Body Fat (\%) & $23.24( \pm 9.23)$ & $23.92( \pm 8.99)$ & $0.70( \pm 2.92)$ \\
\hline BMl & $23.20( \pm 3.81)$ & $23.47( \pm 4.58)$ & $0.03( \pm 0.90)$ \\
\hline Height (m) & $1.67( \pm 0.08)$ & $1.67( \pm 0.8)$ & - \\
\hline Age & $19.04( \pm 2.23)$ & - & - \\
\hline Gender & 151 (77.04\%) Females & 120 (76.92\%) Female & - \\
\hline
\end{tabular}

\section{Discussion}

The aim of current study was to explore how a set of dispositional factors changed and how these changes related to weight and body fat change during the first 3 months of university. Studies using regression-based analysis of the whole sample may highlight findings that generalize across the sample but may miss relationships important for sub-groups due to individual variation. By contrast, our study aimed to identify variables important for sample sub-groups - the evolution over time of predictor and outcome variables that were especially salient to each sub-group. This would allow for a more nuanced understanding of how groups of people may differ in the set of variables relevant to their weight change. Furthermore, by looking at how predictor variables clustered in terms of their relevance to specific participant subgroups, our analysis acknowledges that critical study

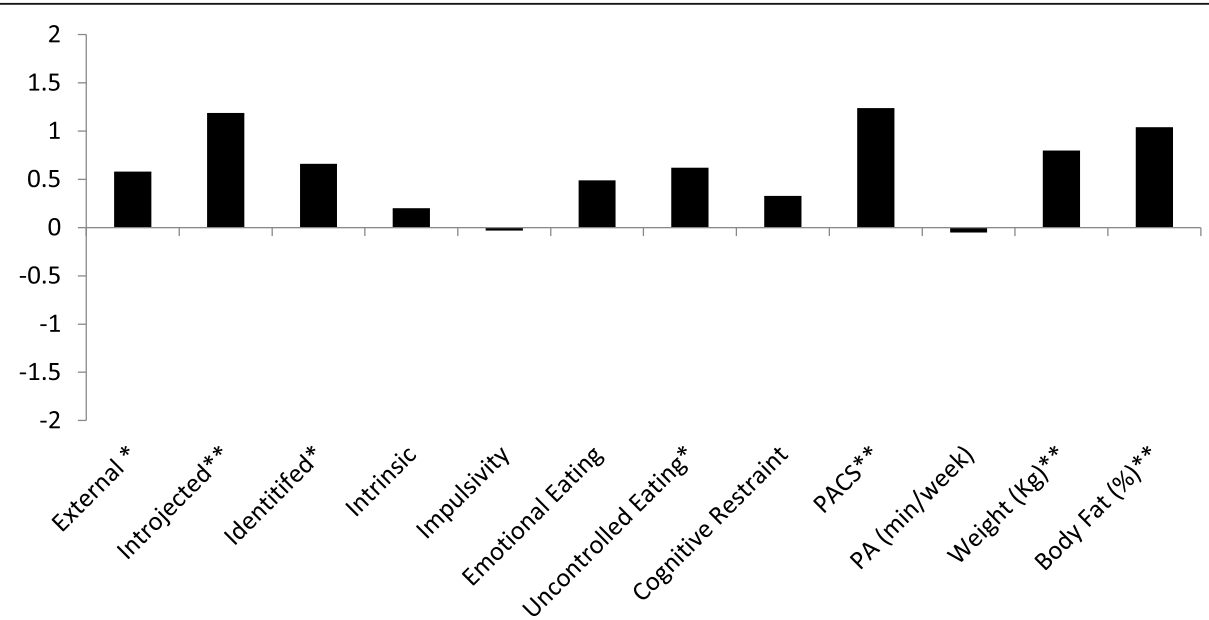

Fig. 1 Cohen's $d$ values for the Gaining Cluster. ${ }^{*}$ Represent a medium effect size $(d= \pm 0.5)$. ${ }^{* *}$ Represents a large effect size $(d= \pm 0.8)$ 
Table 3 Means (SD) and change score of the Gaining Cluster, and The Losing Cluster

\begin{tabular}{|c|c|c|c|c|c|c|}
\hline & \multicolumn{3}{|l|}{ Gaining Cluster } & \multicolumn{3}{|l|}{ Losing Cluster } \\
\hline & $\mathrm{T} 1$ & $\mathrm{~T} 2$ & Change & $\mathrm{T} 1$ & $\mathrm{~T} 2$ & Change \\
\hline \multicolumn{7}{|l|}{ Controlled Motivation } \\
\hline External & $1.88( \pm 0.94)$ & $2.22( \pm 0.98)$ & $1.47^{\mathrm{a}}$ & $2.15( \pm 0.82)$ & $2.47( \pm 0.80)$ & 0.32 \\
\hline Introjected & $2.94( \pm 1.31)$ & $3.41( \pm 1.10)$ & $0.46^{\mathrm{a}}$ & $3.64( \pm 1.05)$ & $4.20( \pm 1.25)$ & 0.29 \\
\hline \multicolumn{7}{|l|}{$\begin{array}{l}\text { Autonomous } \\
\text { Motivation }\end{array}$} \\
\hline Identified & $3.65( \pm 1.04)$ & $3.68( \pm 0.82)$ & $0.02^{\mathrm{a}}$ & $4.13( \pm 0.67)$ & $4.20( \pm 0.60)$ & 0.07 \\
\hline Intrinsic & $3.04( \pm 1.07)$ & $3.25( \pm 1.13)$ & 0.22 & $3.55( \pm 0.75)$ & $4.12( \pm 0.66)$ & $0.57^{\mathrm{a}}$ \\
\hline Impulsivity & $63.71( \pm 9.98)$ & $78.18( \pm 14.95)$ & 14.47 & $64.40( \pm 11.84)$ & $78.93( \pm 15.00)$ & 14.53 \\
\hline \multicolumn{7}{|l|}{ Eating Styles } \\
\hline Emotional Eating & $7.57( \pm 2.78)$ & $8.43( \pm 2.19)$ & 0.86 & $7.80( \pm 3.14)$ & $8.07( \pm 2.69)$ & 0.27 \\
\hline Uncontrolled Eating & $21.25( \pm 5.86)$ & $23.24( \pm 5.78)$ & $1.98^{\mathrm{a}}$ & $24.07( \pm 6.25)$ & $22.53( \pm 6.51)$ & $-1.53^{\mathrm{a}}$ \\
\hline Cognitive Restraint & $13.82( \pm 4.39)$ & $14.92( \pm 4.06)$ & 1.10 & $15.60( \pm 3.83)$ & $20.93( \pm 3.61)$ & $5.33^{\mathrm{a}}$ \\
\hline PACS & $15.43( \pm 4.32)$ & $16.90( \pm 3.93)$ & $1.47^{\mathrm{a}}$ & $17.20( \pm 4.92)$ & $15.87( \pm 4.60)$ & $-1.33^{\mathrm{a}}$ \\
\hline PA (min/week) & $494.61( \pm 355.33)$ & $449.22( \pm 339.93)$ & -45.39 & $357.13( \pm 239.99)$ & $295.00( \pm 246.72)$ & -62.13 \\
\hline Weight (Kg) & $62.95( \pm 10.13)$ & $64.32( \pm 10.46)$ & $1.37^{\mathrm{a}}$ & $68.80( \pm 13.25)$ & $65.35( \pm 12.82)$ & $-3.45^{\mathrm{a}}$ \\
\hline Body Fat (\%) & $25.50( \pm 9.27)$ & $26.79( \pm 9.27)$ & $1.28^{\mathrm{a}}$ & $29.06( \pm 7.49)$ & $27.45( \pm 8.09)$ & $-1.61^{\mathrm{a}}$ \\
\hline
\end{tabular}

${ }^{a}$ represents meaningful changes

variables may be co-dependent - operating as nonindependent sets rather than in isolation.

It was predicted that people who gained weight and body fat would be typified by increased controlled motivation (external regulation and introjected regulation), decreased autonomous motivation (identified regulation and intrinsic motivation), increased impulsivity, increased emotional eating, increased uncontrolled eating, increased physical appearance comparison, and decreased physical activity. By contrast, those who lost weight and body fat would be typified by a converse pattern. There was partial support for the hypotheses; two clusters evidenced changes in weight/body fat with several variables following the predicted patterns. It should be noted that, overall, participants in the current study are slightly lighter than population averages [71] but are comparable to previous research $[6,35]$ looking at weight change in university students in the UK.

The Gaining cluster was characterized by increases in weight/body fat across the study period. The weight gain was approximately double what previous UK research has reported over the same timeframe $(0.83 \mathrm{~kg}$ [6];) but less compared to North American studies [7, 72]. This cluster also gained approximately double the amount of body fat compared to what was reported by Hoffman et al. [5] (0.9\%), one of only a few studies we are aware

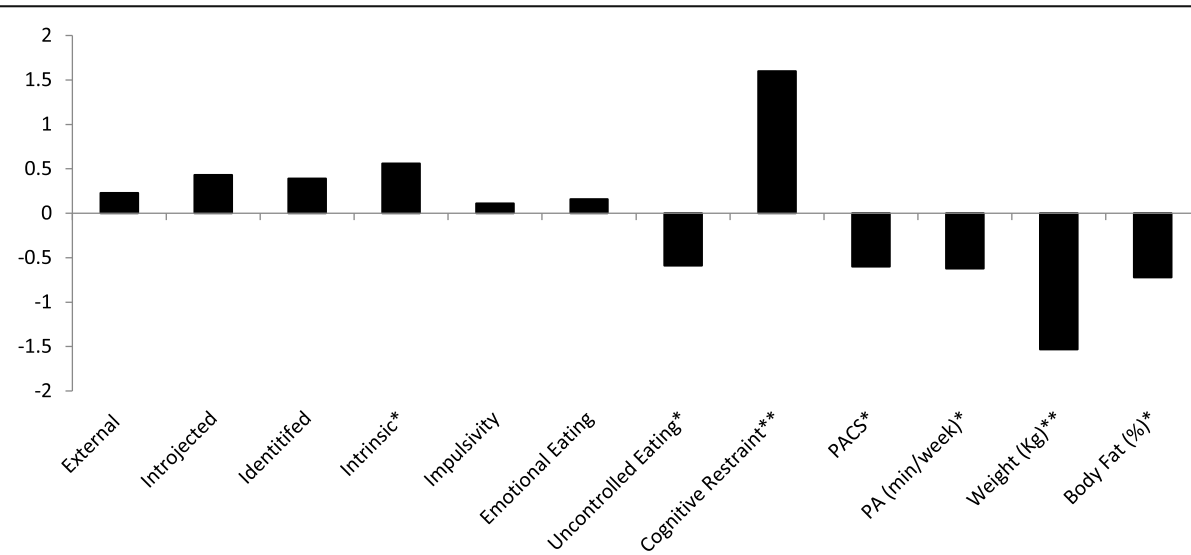

Fig. 2 Cohen's $d$ values for the Losing Cluster. *Represent a medium effect size $(d= \pm 0.5)$. ${ }^{* *}$ Represents a large effect size $(d= \pm 0.8)$ 


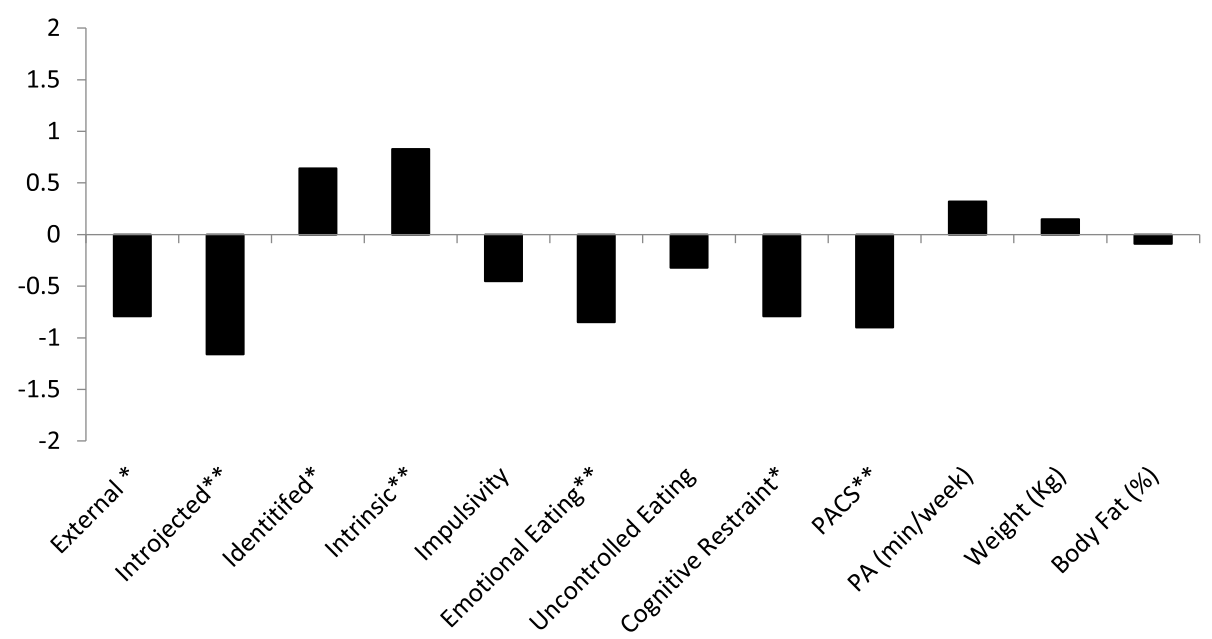

Fig. 3 Cohen's $d$ values for the No Change-High Autonomous Cluster. * Represent a medium effect size $(d= \pm 0.5)$. ${ }^{*}$ Represents a large effect size $(d= \pm 0.8)$

of that reported change in body fat among university students.

The Gaining cluster evidenced an increase in identified regulation. Despite evidence showing that identified regulation is related to weight loss and greater behavioural persistence $[73,74]$, the benefits may have been offset by the increase in controlled motivation (which was predicted to be associated with weight gain). Furthermore, the negative effects of controlled motivation were compounded by an increase in physical appearance comparison. Students high in physical appearance comparison are more likely to focus on external cues, such as perceived norms, and are more likely to feel pressure to act in accordance to those norms (i.e. controlled motivation) $[24,44,46,47,52,75]$. In the context of the current study, there would be a decrease in healthy eating when no longer in a social group that encourages it. A further risk factor for the Gaining cluster was the increase in uncontrolled eating. Findings were consistent with our prediction and accord with previous research $[6,33]$.

Table 4 Means (SD) and change score of the No-Change and High Autonomous Cluster, and The No Change-Low Autonomous Cluster

\begin{tabular}{|c|c|c|c|c|c|c|}
\hline & \multicolumn{3}{|c|}{ No Change-High Autonomous } & \multicolumn{3}{|c|}{ No Change-Low Autonomous } \\
\hline & $\mathrm{T1}$ & $\mathrm{T} 2$ & Change & $\mathrm{T1}$ & $\mathrm{T} 2$ & Change \\
\hline \multicolumn{7}{|l|}{ Controlled Motivation } \\
\hline External & $1.78( \pm 0.80)$ & $1.87( \pm 0.84)$ & $0.08^{\mathrm{a}}$ & $1.80( \pm 0.78)$ & $2.10( \pm 1.06)$ & 0.30 \\
\hline Introjected & $2.93( \pm 1.29)$ & $2.69( \pm 1.22)$ & $-0.25^{\mathrm{a}}$ & $2.88( \pm 1.37)$ & $2.42( \pm 1.30)$ & $-0.46^{\mathrm{a}}$ \\
\hline \multicolumn{7}{|l|}{ Autonomous Motivation } \\
\hline Identified & $3.87( \pm 0.78)$ & $4.02( \pm 0.68)$ & $0.16^{\mathrm{a}}$ & $3.78( \pm 0.94)$ & $3.24( \pm 0.95)$ & $-0.54^{a}$ \\
\hline Intrinsic & $3.41( \pm 1.01)$ & $3.80( \pm 0.93)$ & $0.39^{\mathrm{a}}$ & $3.52( \pm 0.96)$ & $2.63( \pm 0.98)$ & $-0.88^{\mathrm{a}}$ \\
\hline Impulsivity & $62.60( \pm 8.93)$ & $77.14( \pm 12.99)$ & 14.54 & $64.92( \pm 11.98)$ & $79.54( \pm 18.56)$ & 14.62 \\
\hline \multicolumn{7}{|l|}{ Eating Styles } \\
\hline Emotional Eating & $6.30( \pm 2.67)$ & $5.26( \pm 2.33)$ & $-1.04^{\mathrm{a}}$ & $6.78( \pm 2.49)$ & $6.15( \pm 1.91)$ & -0.65 \\
\hline Uncontrolled Eating & $19.58( \pm 5.48)$ & $19.56( \pm 5.39)$ & -0.02 & $21.38( \pm 5.46)$ & $20.19( \pm 4.66)$ & -1.19 \\
\hline Cognitive Restraint & $14.66( \pm 3.74)$ & $14.78( \pm 4.79)$ & $0.12^{\mathrm{a}}$ & $15.46( \pm 4.31)$ & $12.65( \pm 3.91)$ & $-2.81^{\mathrm{a}}$ \\
\hline PACS & $14.94( \pm 3.39)$ & $13.90( \pm 3.63)$ & $-1.04^{\mathrm{a}}$ & $16.00( \pm 3.36)$ & $13.81( \pm 3.90)$ & -2.19 \\
\hline PA (min/week) & $551.06( \pm 383.43)$ & $529.24( \pm 458.09)$ & $-21.82)$ & $442.31( \pm 273.85)$ & $434.04( \pm 238.18)$ & -8.27 \\
\hline Weight (Kg) & $63.16( \pm 10.83)$ & $63.62( \pm 11.39)$ & 0.46 & $64.33( \pm 12.34)$ & $64.79( \pm 13.07)$ & 0.46 \\
\hline Body Fat (\%) & $18.98( \pm 8.70)$ & $19.91( \pm 7.97)$ & 0.93 & $23.63( \pm 7.86)$ & $23.97( \pm 8.12)$ & 0.34 \\
\hline
\end{tabular}

${ }^{a}$ Represents meaningful changes 


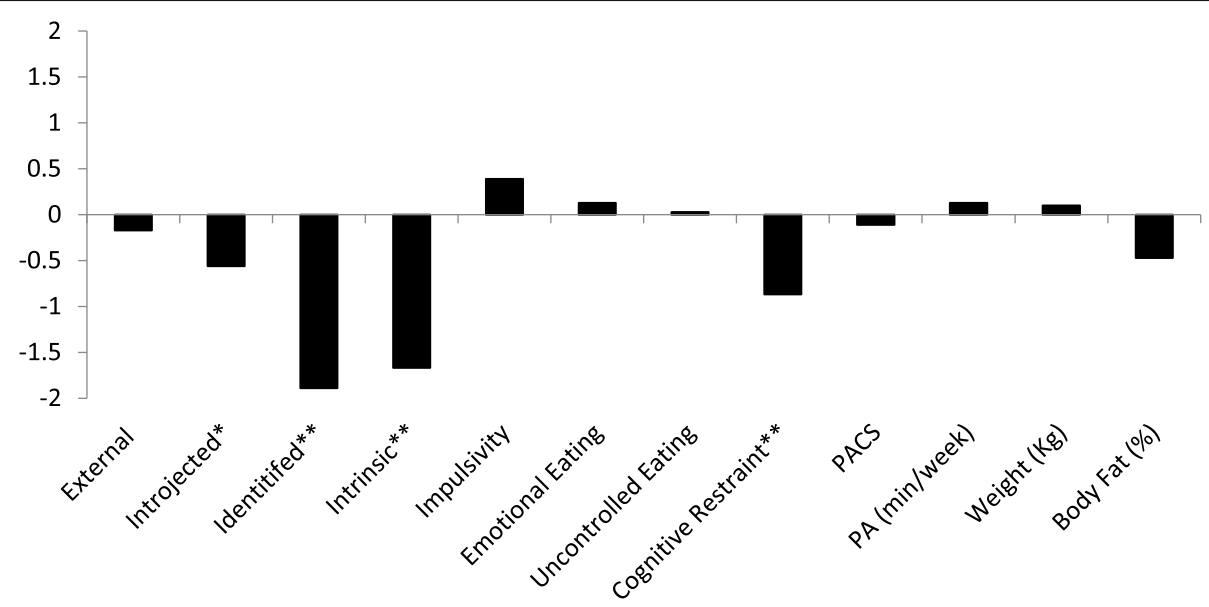

Fig. 4 Cohen's $d$ values for the No Change-Low Autonomous Cluster. *Represent a medium effect size $(d= \pm 0.5)$. **Represents a large effect size $(d= \pm 0.8)$

Regarding the Losing cluster, a loss of $3.45 \mathrm{~kg}$ and of $1.61 \%$ body fat were key differentiating characteristics compared to the other clusters. Previous research reported similar losses with both Serlachius et al. [35] and Jung et al. [76] reporting weight loss of between 2 and 3 $\mathrm{kg}$. The Losing cluster showed an increase in intrinsic motivation - a factor identified as important for following a healthy lifestyle [25-27]. Along with increased intrinsic motivation, the Losing cluster also showed a notable reduction in physical appearance comparison, supporting the study hypotheses. We speculate that individuals in the Losing cluster were more likely to follow a healthy diet because they chose to do so and were less influenced by their social groupings and accompanying perceived norms $[13,49,52]$. Future research may want to explore this further by looking at the way those who are intrinsically motivated to eat healthily make food decisions while eating in social groups.

Compared to other clusters, the Losing cluster also showed a notable increase in cognitive restraint and a decrease in uncontrolled eating. Pliner and Saunders [19] found that cognitive restraint was associated with weight gain. In contrast, Delinsky and Wilson [41] found that a combination of cognitive restraint and concern for weight gain was positively related to weight loss in first year university students. Our interpretation of the current findings is that cognitive restraint acted as protection against weight gain because the students were less likely to binge eat (shown by a decrease in uncontrolled eating) and were more aware of and enjoyed a healthy diet (seen by the increase in intrinsic motivation). This highlights the need to study related sets of psychological factors when exploring weight change; health-related behaviours may arise from interacting psychological factors rather than factors in isolation.
Finally, the Losing cluster also showed a decrease in the amount of time spent doing physical activity. This contradicts previous research in university students $[17,18,76]$ but is more line with recent research highlighting how physical activity is not an effective method for weight loss because food intake increases to balance the energy deficit arising from increased physical activity, and increases in muscle mass can offset any weight loss through fat reduction [77-81].

Findings also identified two clusters where weight/ body fat remained largely stable: A No change-Low autonomous motivation cluster and a No change-High autonomous cluster. The No change-Low autonomous motivation cluster showed a non-meaningful gain of half a kilogram and a negligible change in body fat. This cluster showed decreases in introjected regulation, autonomous motivation, and cognitive restraint. Even though it would have been expected that a decrease in autonomous motivation would be related to an increase in weight, those in this cluster may have been protected because there was an accompanying decrease in introjected regulation, a facet of controlled motivation [73, $74,82-84]$. That is to say, it appeared that participants were not motivated to eat healthily but it is also likely they were not eating unhealthily either. They were also less at risk of binge eating through the decrease in cognitive restraint $[19,41,85,86]$. The No change-high autonomous cluster showed a small non-meaningful gain of half a kilogram and just over half a percent of body fat. There was a decrease in controlled motivation which was accompanied by a corresponding increase in autonomous motivation and a decrease in physical appearance comparison. This meant they were less likely to focus on external cues. People in this cluster also evidenced a decrease in cognitive restraint and emotional eating. Once again, the risk of weight gain associated 
with cognitive restraint may have depended on changes in other traits. In this case, even though the No changehigh autonomous cluster was not restricting diet to control weight, they were less likely to turn to food during times of emotional distress (indicated by the decrease in emotional eating) and they were autonomously choosing to eat healthily. Again, findings are consistent with health behaviours arising from sets of interacting psychological factors rather than factors in isolation.

Consistent with previous research, the current findings showed that entering university represents a critical period where healthy habits are in flux. The results indicated that when individuals are in a new environment, psychological traits can change and may influence the development of healthy habits. When developing interventions, it is important to look at a collective of psychological variables because, as the current results indicate, sets of variables appear to operate together and interactions could impact on whether a variable is considered a risk factor for weight gain. An interaction between psychological variables may also help explain seemingly contradictory research findings. Furthermore, the results of the current study reinforce the need to take a personcentred approach and not assume that groups of individuals are homogenous in the way that underlying psychological variables change despite similar outcomes. In the current study there were two groups that were able to maintain their weight but had different underlying psychological traits.

Notwithstanding the above, the study had several limitations. First, we examined only the first 3 months at university, which limits conclusions regarding longerterm risks of weight/body fat gain. Even though previous research has indicated the majority of weight gain occurs in the first semester (approximately first 3 months of university) $[6,9,87]$, some studies find that students weight continues to change beyond this point $[6,9,88]$.

A second limitation is the sample size and the recruitment method. This study had 196 participants at baseline but previous studies have had larger samples (the average is 412 students when calculated across 17 studies (identified as most relevant to the current research) $[6-11,19,35,41$, 42, 76, 87-91]. However, our analysis using effect sizes allowed us to identify associations that were meaningful given the current sample size. An additional issue for the sampling, which applies to any study involving participants having their weight measured, is a self-selection bias wherein those who are overweight may be more reluctant to participate [41, 88]. If participants expressed any concern regarding being weighed, they were told that they did not need to be informed of the number on the scale and that all information would be kept confidential. We are aware of only one participant who indicated that being weighed was the reason for not continuing with the study.
Further research is needed to address the limitations of the current study, especially regarding the problem encountered with the measure of alcohol consumption (see footnote above) and the modest follow up period. In addition, the current study did not incorporate a measure to assess drug intake or control circadian rhythmicity. Both drug use and circadian rhythmicity have been linked to impulsivity and weight gain [92, 93]. Explorations that extend into the later years of university would permit establishing whether critical study variables are associated with further weight/body fat change and changes in long term health behaviours in general. Research into the development of an intervention targeted at individuals who exhibit the cluster of traits identified as risk factors in the current study may also help to further explain the role they play in weight change during the first year at university.

\section{Conclusions}

Entering university is a significant time of change and this can influence the development of (un) healthy habits. Previous research has typically used analyses which assume relationships between predictors and outcomes are homogenous across the sample. However, the current findings show this assumption may be misplaced. Examining distinct clusters of participants allowed for a more nuanced evaluation of the role of each variable in relation to weight gain. Even though there were distinct patterns of change for weight loss and weight gain across the four clusters, there were two unique patterns of change in psychological variables for those who were able to maintain their weight over the course of 3 months. This reinforces the idea that a onesizes-fits-all approach may not be optimal for developing interventions to prevent the development of unhealthy habits and associated weight gain. Rather, different underlying psychological profiles can be associated with similar weight outcomes, and the relationship of a single variable with weight change may be impacted by other psychological factors.

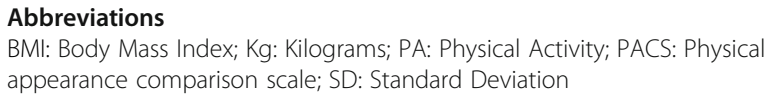

\section{Acknowledgements}

Not applicable.

\section{Authors' contributions}

PFC designed the study, collected and analysed all the data, and was primary author. RL provided guidance for the study design and analysis, and significantly contributed to the writing of the manuscript. ML provided guidance for the study design and reviewed the manuscript. All authors have read and approved the manuscript.

Funding

No funding was provided for this study. 


\section{Availability of data and materials}

The dataset used in the analysis is available from the corresponding author upon request.

\section{Declarations}

\section{Ethics approval and consent}

Ethical approval was given by the Swansea University psychology departmental research ethics committee. All participants were provided with an information sheet and required to sign a consent form prior to taking part in the study.

\section{Consent for publication}

Not applicable.

\section{Competing interests}

The authors have no competing interests to declare.

\section{Author details}

${ }^{1}$ Centre for Trials Research, Cardiff University, Cardiff, UK. ${ }^{2}$ Psychology

Department, Swansea University, Swansea, UK.

Received: 31 March 2020 Accepted: 28 June 2021

Published online: 08 July 2021

\section{References}

1. Adriaanse MA, de Ridder DT, de Wit JB. Finding the critical cue: implementation intentions to change one's diet work best when tailored to personally relevant reasons for unhealthy eating. Personal Soc Psychol Bull. 2009;35(1):60-71. https://doi.org/10.1177/0146167208325612.

2. Neal DT, Wood W, Labrecque JS, Lally P. How do habits guide behavior? Perceived and actual triggers of habits in daily life. J Exp Soc Psychol. 2012; 48(2):492-8. https://doi.org/10.1016/j.jesp.2011.10.011.

3. Neal DT, Wood W, Wu M, Kurlander D. The pull of the past:when do habits persist despite conflict with motives? Personal Soc Psychol Bull. 2011;37(11): 1428-37. https://doi.org/10.1177/0146167211419863.

4. De Bruijn G-J. Understanding college students' fruit consumption. Integrating habit strength in the theory of planned behaviour. Appetite. 2010;54(1):16-22. https://doi.org/10.1016/j.appet.2009.08.007.

5. Hoffman DJ, Policastro P, Quick V, Lee SK. Changes in body weight and fat mass of men and women in the first year of college: a study of the "freshman 15". J Am Coll Health. 2006;55(1):41-5. https://doi.org/10.3200/JA CH.55.1.41-46.

6. Finlayson G, Cecil J, Higgs S, Hill A, Hetherington M. Susceptibility to weight gain. Eating behaviour traits and physical activity as predictors of weight gain during the first year of university. Appetite. 2012;58(3):1091-8. https:// doi.org/10.1016/.j.appet.2012.03.003.

7. Wengreen $\mathrm{HJ}$, Moncur $\mathrm{C}$. Change in diet, physical activity, and body weight among young-adults during the transition from high school to college. Nutr J. 2009;8(1):32. https://doi.org/10.1186/1475-2891-8-32.

8. Edmonds MJ, Ferreira KJ, Nikiforuk EA, Finnie AK, Leavey SH, Duncan AM, et al. Body weight and percent body fat increase during the transition from high school to university in females. J Am Diet Assoc. 2008;108(6):1033-7. https://doi.org/10.1016/j.jada.2008.03.002.

9. Holm-Denoma JM, Joiner TE, Vohs KD, Heatherton TF. The "freshman fifteen" (the "freshman five" actually): predictors and possible explanations. Health Psychol. 2008;27(1s):S3-9. https://doi.org/10.1037/0278-6133.27.1.S3.

10. Levitsky DA, Halbmaier CA, Mrdjenovic G. The freshman weight gain: a model for the study of the epidemic of obesity. Int J Obes. 2004;28(11): 1435-42. https://doi.org/10.1038/sj.jjo.0802776.

11. Kasparek DG, Corwin SJ, Valois RF, Sargent RG, Morris RL. Selected health behaviors that influence college freshman weight change. J Am Coll Heal. 2008;56(4):437-44. https://doi.org/10.3200/JACH.56.44.437-444.

12. Brevard PB, Ricketts CD. Residence of college students affects dietary intake, physical activity, and serum lipid levels. J Am Diet Assoc. 1996;96(1):35-8. https://doi.org/10.1016/S0002-8223(96)00011-9.

13. Greaney ML, Less FD, White AA, Dayton SF, Riebe D, Blissmer B, et al. College students' barriers and enablers for healthful weight management: a qualitative study. J Nutr Educ Behav. 2009;41(4):281-6. https://doi.org/10.101 6/j.jneb.2008.04.354.
14. Nelson MC, Kocos R, Lytle LA, Perry CL. Understanding the perceived determinants of weight-related behaviors in late adolescence: a qualitative analysis among college youth. J Nutr Educ Behav. 2009;41(4):287-92. https://doi.org/10.1016/j.jneb.2008.05.005.

15. Nelson Laska M, Larson NI, Neumark-Sztainer D, Story M. Dietary patterns and home food availability during emerging adulthood: do they differ by living situation? Public Health Nutr. 2010;13(2):222-8. https://doi.org/10.101 7/S1368980009990760

16. Yeh M-C, Matsumori B, Obenchain J, Viladrich A, Das D, Navder K. Validity of a competing food choice construct regarding fruit and vegetable consumption among Urban College freshmen. J Nutr Educ Behav. 2010; 42(5):321-7. https://doi.org/10.1016/j.jneb.2009.08.004.

17. Butler SM, Black DR, Blue CL, Gretebeck RJ. Change in diet, physical activity, and body weight in female college freshman. Am J Health Behav. 2004; 28(1):24-32. https://doi.org/10.5993/AJHB.28.1.3.

18. Mifsud G, Duval K, Doucet É. Low body fat and high cardiorespiratory fitness at the onset of the freshmen year may not protect against weight gain. $\mathrm{Br} J$ Nutr. 2009;101(9):1406-12. https:/doi.org/10.1017/S0007114508067639.

19. Pliner $P$, Saunders $T$. Vulnerability to freshman weight gain as a function of dietary restraint and residence. Physiol Behav. 2008;93(1):76-82. https://doi. org/10.1016/.j.physbeh.2007.07.017.

20. De Vries H, van't Riet J, Spigt M, Metsemakers J, van den Akker M, Vermunt $J \mathrm{~K}$, et al. Clusters of lifestyle behaviors: results from the Dutch SMILE study. Prev Med. 2008;46(3):203-8. https://doi.org/10.1016/j.ypmed.2007.08.005.

21. Hendricks KM, Herbold N, Fung T. Diet and other lifestyle behaviors in young college women. Nutr Res. 2004;24(12):981-91. https://doi.org/10.101 6/j.nutres.2004.09.004.

22. Ryan RM, Deci EL. Intrinsic motivation and self-determination in human behaviour. New York: Plenum; 1985.

23. Deci EL, Ryan RM. Self-determination theory: a macrotheory of human motivation, development, and health. Can Psychol. 2008;49(3):182-5. https:// doi.org/10.1037/a0012801.

24. Vansteenkiste M, Niemiec Christopher P, Soenens B. The development of the five mini-theories of self-determination theory: an historical overview, emerging trends, and future directions, The Decade Ahead: Theoretical Perspectives on Motivation and Achievement. Advances in Motivation and Achievement: 16 Part A. Bingley, UK: Emerald Group Publishing Limited; 2010. p. 105-65.

25. Furia AC, Lee RE, Strother ML, Huang TT. College students' motivation to achieve and maintain a healthy weight. Am J Health Behav. 2009;33(3):25663. https://doi.org/10.5993/ajhb.33.3.4.

26. LaCaille LJ, Dauner KN, Krambeer RJ, Pedersen J. Psychosocial and environmental determinants of eating behaviors, physical activity, and weight change among college students: a qualitative analysis. J Am Coll Heal. 2011;59(6):531-8. https://doi.org/10.1080/07448481.2010.523855.

27. Quintiliani LM, Bishop HL, Greaney ML, Whiteley JA. Factors across home, work, and school domains influence nutrition and physical activity behaviors of nontraditional college students. Nutr Res. 2012;32(10):757-63. https://doi.org/10.1016/j.nutres.2012.09.008.

28. Walsh JR, White AA, Greaney ML. Using focus groups to identify factors affecting healthy weight maintenance in college men. Nutr Res. 2009;29(6): 371-8. https://doi.org/10.1016/j.nutres.2009.04.002.

29. Barratt ES. The biological basis of impulsiveness: the significance of timing and rhythm disorders. Personal Individ Differ. 1983;4(4):387-91. https://doi. org/10.1016/0191-8869(83)90004-1.

30. Bickel WK, Jarmolowicz DP, Mueller ET, Gatchalian KM, McClure SM. Are executive function and impulsivity antipodes? A conceptual reconstruction with special reference to addiction. Psychopharmacology. 2012;221(3):36187. https://doi.org/10.1007/s00213-012-2689-x.

31. Mullan B, Allom V, Brogan A, Kothe E, Todd J. Self-regulation and the intention behaviour gap. Exploring dietary behaviours in university students. Appetite. 2014;73:7-14. https://doi.org/10.1016/j.appet.2013.10.010.

32. Price $M$, Higgs S, Maw J, Lee M. A dual-process approach to exploring the role of delay discounting in obesity. Physiol Behav. 2016;162:46-51. https:// doi.org/10.1016/j.physbeh.2016.02.020.

33. Greene GW, Schembre SM, White AA, Hoerr SL, Lohse B, Shoff S, et al. Identifying clusters of college students at elevated health risk based on eating and exercise behaviors and psychosocial determinants of body weight. J Am Diet Assoc. 2011;111(3):394-400. https:/doi.org/10.1016/j.jada.2010.11.011. 
34. Tice DM, Bratslavsky E, Baumeister RF. Emotional distress regulation takes precedence over impulse control: If you feel bad, do it! J Pers Soc Psychol. 2001;80(1):53.

35. Serlachius A, Hamer M, Wardle J. Stress and weight change in university students in the United Kingdom. Physiol Behav. 2007;92(4):548-53. https:// doi.org/10.1016/j.physbeh.2007.04.032.

36. Yeomans MR, Leitch M, Mobini S. Impulsivity is associated with the disinhibition but not restraint factor from the three factor eating questionnaire. Appetite. 2008;50(2):469-76. https://doi.org/10.1016/j.appet.2 007.10.002.

37. Chatzisarantis NL, Hagger MS, Biddle SJ, Karageorghis C. The cognitive processes by which perceived locus of causality predicts participation in physical activity. J Health Psychol. 2002;7(6):685-99. https://doi.org/10.11 77/1359105302007006872.

38. Lutz RS, Karoly P, Okun MA. The why and the how of goal pursuit: selfdetermination, goal process cognition, and participation in physical exercise. Psychol Sport Exerc. 2008;9(5):559-75. https://doi.org/10.1016/j. psychsport.2007.07.006.

39. Strachan SM, Fortier MS, Perras MGM, Lugg C. Understanding variations in exercise-identity strength through identity theory and self-determination theory. Int J Sport Exer Psychol. 2013;11(3):273-85. https://doi.org/10.1080/1 612197X.2013.749005.

40. Karlsson J, Persson LO, Sjöström L, Sullivan M. Psychometric properties and factor structure of the three-factor eating questionnaire (TFEQ) in obese men and women. Results from the Swedish obese subjects (SOS) study. Int J Obes. 2000;24(12):1715-25. https://doi.org/10.1038/sj.ijo.0801442.

41. Delinsky SS, Wilson GT. Weight gain, dietary restraint, and disordered eating in the freshman year of college. Eat Behav. 2008;9(1):82-90. https://doi.org/1 0.1016/j.eatbeh.2007.06.001

42. Provencher V, Polivy J, Wintre MG, Pratt MW, Pancer SM, Birnie-Lefcovitch S, et al. Who gains or who loses weight? Psychosocial factors among first-year university students. Physiol Behav. 2009;96(1):135-41.

43. Buunk AP, Gibbons FX. Social comparison: the end of a theory and the emergence of a field. Organ Behav Hum Decis Process. 2007;102(1):3-21. https://doi.org/10.1016/j.obhdp.2006.09.007.

44. Festinger L. A theory of social comparison processes. Hum Relat. 1954;7(2): $117-40$

45. Buunk FXGBP. Individual differences in social comparison: development of a scale of social comparison orientation. J Pers Soc Psychol. 1999;76(1):129-42.

46. Ouellette JA, Hessling R, Gibbons FX, Reis-Bergan M, Gerrard M. Using images to increase exercise behavior: prototypes versus possible selves. Personal Soc Psychol Bull. 2005;31(5):610-20. https://doi.org/10.1177/01461 67204271589

47. Pila E, Stamiris A, Castonguay A, Sabiston CM. Body-Related Envy: A Social Comparison Perspective in Sport and Exercise. J Sport Exerc Psychol. 2014; 36(1):93.

48. Suls J, Martin R, Wheeler L. Social comparison: why, with whom, and with what effect? Curr Dir Psychol Sci. 2002;11(5):159-63. https://doi.org/1 0.1111/1467-8721.00191.

49. Deci EL, Ryan RM. The "what" and "why" of goal pursuits: human needs and the self-determination of behavior. Psychol Inq. 2000;11(4):227-68. https:// doi.org/10.1207/S15327965PLI1104_01.

50. Koestner R, Bernieri F, Zuckerman M. Self-regulation and consistency between attitudes, traits, and behaviors. Personal Soc Psychol Bull. 1992; 18(1):52-9. https://doi.org/10.1177/0146167292181008.

51. Neighbors C, Raymond KC. Self-determination and the consequences of social comparison. J Res Pers. 2003;37(6):529-46. https://doi.org/10.1016/ S0092-6566(03)00047-3.

52. Norman P, Clark T, Walker G. The theory of planned behavior, descriptive norms, and the moderating role of group identification. J Appl Soc Psychol. 2005;35(5):1008-29. https://doi.org/10.1111/j.1559-1816.2005.tb02157.x.

53. Bailey SD, Ricciardelli LA. Social comparisons, appearance related comments, contingent self-esteem and their relationships with body dissatisfaction and eating disturbance among women. Eat Behav. 2010;11(2):107-12. https:// doi.org/10.1016/j.eatbeh.2009.12.001.

54. Hamel AE, Zaitsoff SL, Taylor A, Menna R, Le Grange D. Body-related social comparison and disordered eating among adolescent females with an eating disorder, depressive disorder, and healthy controls. Nutrients. 2012; 4(9):1260-72. https://doi.org/10.3390/nu4091260.

55. Stormer SM, Thompson JK. Explanations of body image disturbance: a test of maturational status, negative verbal commentary, social comparison, and sociocultural hypotheses. Int J Eat Disord. 1996;19(2):193-202. https://doi. org/10.1002/(SICI)1098-108X(199603)19:2<193::AID-EAT10>3.0.CO;2-W.

56. Thompson JK, Coovert MD, Stormer SM. Body image, social comparison, and eating disturbance: a covariance structure modeling investigation. Int J Eat Disord. 1999;26(1):43-51. https://doi.org/10.1002/(SICI)1098-108X(1 99907)26:1<43::AID-EAT6>3.0.CO;2-R.

57. Littlefield AK, Sher KJ, Steinley D. Developmental trajectories of impulsivity and their association with alcohol use and related outcomes during emerging and young adulthood I. Alcohol Clin Exp Res. 2010;34(8):1409-16.

58. Quinn PD, Stappenbeck CA, Fromme K. Collegiate heavy drinking prospectively predicts change in sensation seeking and impulsivity. J Abnorm Psychol. 2011;120(3):543-56. https://doi.org/10.1037/a0023159.

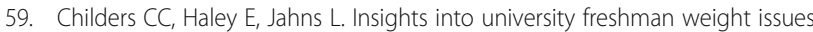
and how they make decisions about eating. J Consum Aff. 2011;45(2):30628. https://doi.org/10.1111/j.1745-6606.2011.01204.x.

60. Deliens T, Clarys P, De Bourdeaudhuij I, Deforche B. Determinants of eating behaviour in university students: a qualitative study using focus group discussions. BMC Public Health. 2014;14(1):1-12.

61. Eisenberg ME, Berge JM, Fulkerson JA, Neumark-Sztainer D. Weight comments by family and significant others in young adulthood. Body image. 2011;8(1):12-9. https://doi.org/10.1016/j.bodyim.2010.11.002.

62. Harvey-Berino J, Pope L, Gold BC, Leonard H, Belliveau C. Undergrad and overweight: an online behavioral weight management program for college students. J Nutr Educ Behav. 2012;44(6):604-8. https://doi.org/10.1016/j. jneb.2012.04.016.

63. Lawlor DA, Chaturvedi N. Treatment and prevention of obesity-are there critical periods for intervention? Int J Epidemiol. 2006;35(1):3-9. https://doi. org/10.1093/ije/dyi309.

64. Mullan E, Markland D, Ingledew DK. A graded conceptualisation of selfdetermination in the regulation of exercise behaviour: development of a measure using confirmatory factor analytic procedures. Personal Individ Differ. 1997;23(5):745-52. https://doi.org/10.1016/S0191-8869(97)00107-4

65. Patton JH, Stanford MS, Barratt ES. Factor structure of the barratt impulsiveness scale. J Clin Psychol. 1995;51(6):768-74. https://doi.org/10.1 002/1097-4679(199511)51:6<768::AID-JCLP2270510607>3.0.CO;2-1.

66. Thompson JK, Fabian LJ, Moulton DO, Dunn ME, Altabe MN. Development and validation of the physical appearance related teasing scale. J Pers Assess. 1991;56(3):513-21. https://doi.org/10.1207/s15327752jpa5603_12.

67. Sallis JF, Buono MJ, Roby JJ, Micale FG, Nelson JA. Seven-day recall and other physical activity self-reports in children and adolescents. Med Sci Sports Exerc. 1993;25(1):99-108. https://doi.org/10.1249/00005768-199301 000-00014.

68. Lowe R, Eves F, Carroll D. The influence of affective and instrumental beliefs on exercise intentions and behavior: a longitudinal analysis. J Appl Soc Psychol. 2002;32(6):1241-52. https://doi.org/10.1111/j.1559-1816.2002. tb01434.x.

69. Tanita. How Tanita BIA technology works 2012 [Available from: http://www. tanita.eu/tanita-bia-technology.html.

70. Clatworthy J, Hankins M, Buick D, Weinman J, Horne R. Cluster analysis in illness perception research: a Monte Carlo study to identify the most appropriate method. Psychol Health. 2007;22(2):123-42. https://doi.org/10.1 080/14768320600774496.

71. Lifestyles Team ND. Health Survey For England. In: Centre HaSCl, editor. https://digital.nhs.uk/data-and-information/publications/statistical/healthsurvey-for-england/2019 Health and Social Care Information Centre; 2020.

72. Crombie AP, Liu P-Y, Ormsbee MJ, llich JZ. Weight and body-composition change during the college freshman year in male general-population students and army reserve officer training corps (ROTC) cadets. Int I Sport Nutr Exerc Metab. 2012;22(6):412-21. https://doi.org/10.1123/ijsnem.22.6.412.

73. Vieira PN, Mata J, Silva MN, Coutinho SR, Santos TC, Minderico CS, et al. Predictors of psychological well-being during behavioral obesity treatment in women. J Obes. 2010;2011:936153.

74. Williams GC, Grow VM, Freedman ZR, Ryan RM, Deci EL. Motivational predictors of weight loss and weight-loss maintenance. J Pers Soc Psychol. 1996;70(1):115-26. https://doi.org/10.1037/0022-3514.70.1.115.

75. Thøgersen-Ntoumani C, Ntoumanis N. A self-determination theory approach to the study of body image concerns, self-presentation and self-perceptions in a sample of aerobic instructors. J Health Psychol. 2007;12(2):301-15. https://doi.org/10.1177/1359105307074267.

76. Jung ME, Bray SR, Martin Ginis KA. Behavior change and the freshman 15: tracking physical activity and dietary patterns in 1st-year university women. 
J Am Coll Health. 2008;56(5):523-30. https://doi.org/10.3200/JACH.56.5.523530.

77. Hjorth MF, Chaput JP, Ritz C, Dalskov SM, Andersen R, Astrup A, et al. Fatness predicts decreased physical activity and increased sedentary time, but not vice versa: support from a longitudinal study in 8- to 11-year-old children. Int J Obes. 2014;38(7):959-65. https://doi.org/10.1038/ijo.2013.229.

78. Jakicic JM, Davis KK, Rogers RJ, King WC, Marcus MD, Helsel D, et al. Effect of wearable technology combined with a lifestyle intervention on longterm weight loss: the IDEA randomized clinical trial. JAMA. 2016;316(11): 1161-71. https://doi.org/10.1001/jama.2016.12858.

79. May AM, Bueno-de-Mesquita HB, Boshuizen H, Spijkerman AM, Peeters PH, Verschuren WM. Effect of change in physical activity on body fatness over a 10-y period in the Doetinchem cohort study. Am J Clin Nutr. 2010;92(3): 491-9. https://doi.org/10.3945/ajcn.2010.29404.

80. Mekary RA, Grøntved A, Despres J-P, De Moura LP, Asgarzadeh M, Willett WC, et al. Weight training, aerobic physical activities, and long-term waist circumference change in men. Obesity. 2015;23(2):461-7. https://doi.org/1 0.1002/oby.20949.

81. Whybrow S, Hughes DA, Ritz P, Johnstone AM, Horgan GW, King N, et al. The effect of an incremental increase in exercise on appetite, eating behaviour and energy balance in lean men and women feeding ad libitum. Br J Nutr. 2008;100(5):1109-15. https://doi.org/10.1017/50007114508968240.

82. Cluskey M, Grobe D. College weight gain and behavior transitions: male and female differences. J Am Diet Assoc. 2009;109(2):325-9. https://doi. org/10.1016/j.jada.2008.10.045.

83. French SA, Epstein LH, Jeffery RW, Blundell JE, Wardle J. Eating behavior dimensions. Associations with energy intake and body weight. A review. Appetite. 2012;59(2):541-9. https://doi.org/10.1016/j.appet.2012.07.001.

84. Nederkoorn C, Guerrieri R, Havermans RC, Roefs A, Jansen A. The interactive effect of hunger and impulsivity on food intake and purchase in a virtual supermarket. Int J Obes. 2009;33(8):905-12. https://doi.org/10.1038/ijo.2009. 98.

85. Mills JS, Palandra A. Perceived caloric content of a preload and disinhibition among restrained eaters. Appetite. 2008;50(2):240-5. https://doi.org/10.1016/ j.appet.2007.07.007.

86. Vohs KD, Heatherton TF. Self-regulatory failure: a resource-depletion approach. Psychol Sci. 2000;11(3):249-54. https://doi.org/10.1111/1467-9280. 00250.

87. Mazzeo RWGSETSE. Preventing weight gain in first year college students: an online intervention to prevent the "freshman fifteen". Eat Behav. 2010;11:339.

88. Anderson DA, Shapiro JR, Lundgren JD. The freshman year of college as a critical period for weight gain: an initial evaluation. Eat Behav. 2003;4(4): 363-7. https://doi.org/10.1016/S1471-0153(03)00030-8.

89. Gropper SS, Simmons KP, Gaines A, Drawdy K, Saunders D, Ulrich P, et al. The freshman 15-a closer look. J Am College Health. 2009;58(3):223-31. https://doi.org/10.1080/07448480903295334.

90. Lloyd-Richardson EE, Bailey S, Fava JL, Wing R. A prospective study of weight gain during the college freshman and sophomore years. Prev Med. 2009;48(3):256-61. https://doi.org/10.1016/j.ypmed.2008.12.009.

91. Yakusheva O, Kapinos K, Weiss M. Peer effects and the freshman 15: evidence from a natural experiment. Economics \& Human Biology. 2011; 9(2):119-32. https://doi.org/10.1016/j.ehb.2010.12.002.

92. Murphy CM, Stojek MK, MacKillop J. Interrelationships among impulsive personality traits, food addiction, and body mass index. Appetite. 2014;73: 45-50. https://doi.org/10.1016/j.appet.2013.10.008.

93. Adan A. A chronobiological approach to addiction. J Subst Abus. 2013;18(3): $171-83$.

\section{Publisher's Note}

Springer Nature remains neutral with regard to jurisdictional claims in published maps and institutional affiliations.

Ready to submit your research? Choose BMC and benefit from:

- fast, convenient online submission

- thorough peer review by experienced researchers in your field

- rapid publication on acceptance

- support for research data, including large and complex data types

- gold Open Access which fosters wider collaboration and increased citations

- maximum visibility for your research: over $100 \mathrm{M}$ website views per year

At BMC, research is always in progress.

Learn more biomedcentral.com/submissions 